\title{
New Insight into minimal architecture based carbon nanotubes anode with improved mechanical properties for Li-ion battery
}

\author{
Satish Teotia ${ }^{1,3}$, B.P. Singh ${ }^{1 *}$, Anisha Chaudhary ${ }^{1}$, Indu Elizabeth \\ Saroj Kumari ${ }^{1}$, S. R. Dhakate ${ }^{1}$, S. Gopukumar ${ }^{2}$, R. B. Mathur ${ }^{1}$ \\ ${ }^{1}$ Advanced Carbon Products, CSIR-National Physical Laboratory, New Delhi 110012, India \\ ${ }^{2}$ CSIR-Central Electro Chemical Research Institute, Karaikudi, Chennai 630006, India \\ ${ }^{3}$ Department of Physics, Banaras Hindu University, Varanasi 221005, UP, India
}

${ }^{*}$ Corresponding author: Tel: (+91) 11-45608460; Fax: (+91)-11-45609310;

E-mail: bps@nplindia.org, bpsingh2k4@yahoo.com

Received: 21 February 2017, Revised: 29 February 2017 and Accepted: 09 April 2017

DOI: $10.5185 /$ amlett.2017.1692

www.vbripress.com/aml

\begin{abstract}
The quick advancement of flexible energy storage gadgets has persuaded individuals to look for reliable electrodes with high mechanical flexibility and remarkable electrochemical performance. In the present study, we demonstrate a simple and scalable process to fabricate a flexible, light-weight, free-standing polyvinylidene fluoride-multiwalled carbon nanotubes (PVDF-MWCNT) composite paper, which can be specifically utilized as a flexible anode for lithium ion batteries (LIBs). The excellent binding of MWCNT with PVDF matrix, developed by a straightforward vacuum filtration process, provides sufficient structural integrity to the composite paper. The breaking strength of the PVDF-MWCNT composite paper so formed is found to be $3.5 \mathrm{MPa}$ with strain to failure of $11.25 \%$. The composite paper so developed shows a good cycle reversible charge capacity when used as anode in a standard Li-ion battery. The PVDF-MWCNT composite paper provides a novel pathway to large scale fabrication of flexible electrodes which can be used without conducting support of copper sheet. Copyright @ 2017 VBRI Press.
\end{abstract}

Keywords: MWCNT, flexible, free-standing, composite, anode, Li-ion battery.

\section{Introduction}

In recent years, the interest of research community is centered on the development of the effective energy storage strategies with the prospective to replace traditional energy sources as well as fulfill the high energy demands of the new generation portable electronic devices. In this view, rechargeable Lithium-ion batteries (LIBs) are perfect candidates for energy storage requirements in various applications due to their high energy and power densities [1]. LIBs are favored over different frameworks as a result of their long cycle life, wide temperature range of operation, low self-release, no memory effect, high performance in terms of energy density and capacity $[\mathbf{2 , 3}$. Additionally, these batteries possess high energy conversion efficiency and zero emissions [4]. A Lithium ion battery/cell consists of a negative electrode, a positive electrode and a separator, soaked in an electrolyte solution. Every electrode is shaped from a metal substrate that is covered with a blend of an active material, an electrical conductor, a binder, and a solvent [5]. A typical anode ought to have a high $\mathrm{Li}$ stockpiling limit and great basic steadiness for long cyclability and cell life. Till date, graphite is the most commonly used anode material as a part of LIB [6]. Thus, the attributes and properties of graphitic carbons have been concentrated widely $[\mathbf{7 , 3 , 8}]$. It is also economical compared with other anode materials and is accessible in vast amount. The theoretical specific capacity of graphite which is $372 \mathrm{mAh} / \mathrm{g}$. However, it is difficult to achieve this capacity in practical terms. A range of carbonaceous materials viz hard carbons, [9] single walled carbon nanotubes (SWCNT), [10,11] multiwalled carbon nanotubes (MWCNT), [12-14] graphene, $[\mathbf{1 5}, \mathbf{1 6}]$ mesocarbon micro beads (MCMB) $[\mathbf{1 7 , 1 8}]$ etc., have been investigated as the anode materials for LIB. Amongst carbon nanostructures, carbon nanotubes (CNTs) have been found very important material in LIBs application. Because of their excellent electrochemical, electrical and mechanical properties these are a promising material for use in LIB [19]. The incorporation of CNTs (rather than conventional carbon) with lower weight loading is used to build up an electrical percolation system effectively. In addition, CNTs have the ability to be assembled into free- 
standing anodes as an active material for lithium ion storage. Free-standing paper electrode has few points of interest, most importantly, elimination of conducting material like carbon black (to increase the conductivity of the anode) and current collector, the dead weight of an electrode is minimized, prompting the expansion of accessible limit and particular energy density of the battery [19] in flexible and lightweight electronic gadget applications.

Several researchers have investigated the electrochemical properties of SWCNTs, [20-22] MWCNTs, [23,24] graphene, [25-27] and grapheneMWCNTs hybrids [28-30] as an electrode for Li-ion batteries. A combination of metal/metal oxide particles on the surface of MWCNTs to increase the charge capacity is also one of the areas of recent research [31-33]. However, the problem of volume expansion of electrode results in the formation of defects in the electrodes after few cycles resulting in a decrease in the cell performance $[\mathbf{3 4}, \mathbf{3 5}]$. In one of the studies, Maurin has reported the capacity of $180 \mathrm{mAh} / \mathrm{g}$ for MWCNT based electrode [36]. The MWCNTs used for this purpose were synthesized by an electric-arc technique which is not only very costly but also the CNT soot was full of impurities in the form of catalyst particles, carbon onions and amorphous carbon. Yan et al. prepared different CNT based electrodes and found that a neat CNT electrode exhibits a reversible capacity of only $\sim 120 \mathrm{mAh} / \mathrm{g}$ during the cyclic process, a $\mathrm{TiO}_{2} / \mathrm{CNTs}$ electrode shows reversible capacity of $\sim 145$ $\mathrm{mAh} / \mathrm{g}$ after 30 cycles and the $\mathrm{Ag}-\mathrm{TiO}_{2} / \mathrm{CNTs}$ electrode shows $172 \mathrm{mAh} / \mathrm{g}$ after 30 cycles [37]. Wang et al. used long length CNTs and found the reversible capacity of $290 \mathrm{mAh} / \mathrm{g}$ after 30 cycles with a Coulombic efficiency of $60 \%$ [38]. However, Wang et al. chose the base material as foam Ni plate, but high density of $\mathrm{Ni}$ which in turn accounted for the reduced energy density of the battery. Frackowiak et al. used MWCNTs synthesized at $900{ }^{\circ} \mathrm{C}$ which showed irreversible capacity of $505 \mathrm{mAh} / \mathrm{g}$ in second cycle, which got reduced to $273 \mathrm{mAh} / \mathrm{g}$ only after five cycles [39]. Pure MWCNT based paper is a good alternate over the graphite based anode materials but a sharp decline in the cell performance after few cycles as reported above could be due to disintegration of the CNT paper during charge discharge process. Keeping the above points in view, the present study was undertaken to improve the mechanical properties of the flexible anode without sacrificing its electrochemical performance. In this study, we report the fabrication of highly flexible PVDF-MWCNT composite paper with good mechanical strength and reasonably attractive electrochemical performance.

\section{Experimental}

\section{Synthesis of carbon nanotube}

Carbon nanotubes were synthesized by in-house chemical vapor deposition (CVD) setup reported earlier [40]. Once the temperature was reached, the arrangement containing a solution of ferrocene $\left(\mathrm{Fe}\left(\mathrm{C}_{5} \mathrm{H}_{5}\right)_{2}\right)$ (Loba), an organometallic compound, dissolved in toluene
$\left(\mathrm{C}_{6} \mathrm{H}_{5} \mathrm{CH}_{3}\right)$ (SRL), in specific proportion was introduced in the reaction zone using high purity argon as a carrier gas. MWCNT were grown inside the quartz reactor, which act as a substrate itself, by thermal decomposition of hydrocarbon, in presence of iron catalyst. After the whole solution was consumed the nanotubes were harvested.

\section{Preparation of composite paper anode}

A novel route was followed for the dispersion of PVDF-MWCNT (Alpha Aesar) mix with acetone. PVDF and MWCNTs in specific proportion (10:90 ratio by weight) were mixed with acetone (SRL) by homogenizer (Miccra D-9, from ART Prozess and Labortechnik GmbH and Co. KG) then sonicated in the ultrasonicator bath to make a homogeneous mixture. In this process, the MWCNTs bundles were well de-agglomerated in the PVDF. This homogeneous mixture was transferred to specially designed vacuum filtration unit shown in the Fig. 1.

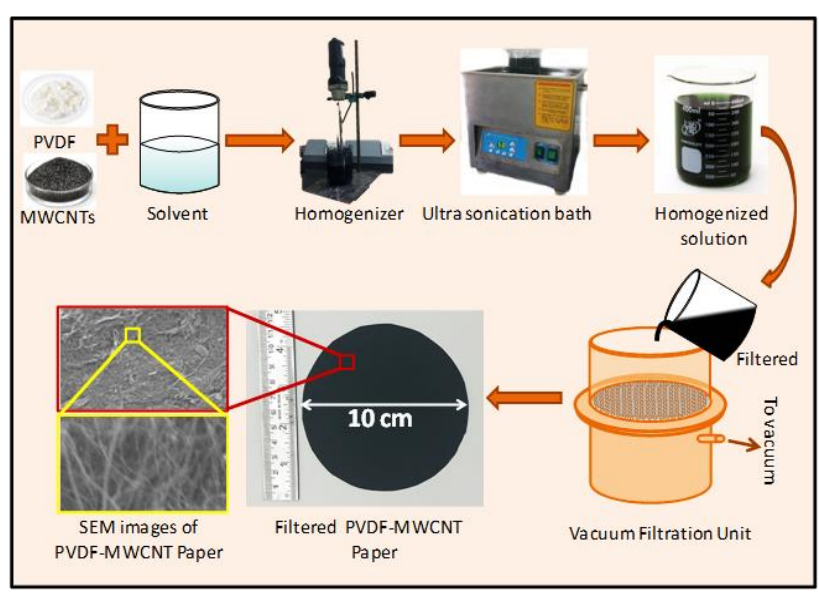

Fig. 1. Schematic of fabrication process for PVDF-MWCNT composite paper.

The composite perform paper was peeled off from the filter paper and dried between stainless steel die plates in oven at $60{ }^{\circ} \mathrm{C}$ to avoid formation of wrinkles due to PVDF-MWCNT interfacial interactions in the paper. MWCNT paper is also prepared by the same method without adding PVDF. The flexibility of the PVDFMWCNT composite paper is shown in Fig. 2.

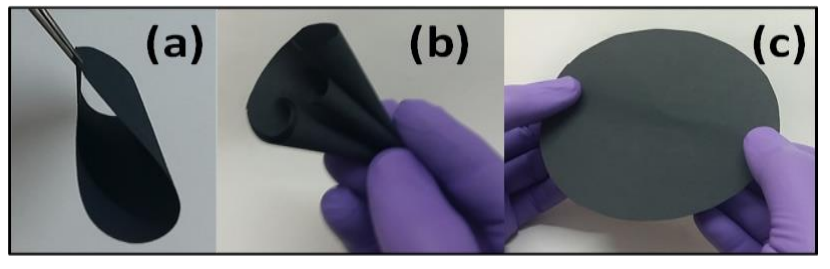

Fig. 2. Digital images of (a) single folded, (b) multiple folded and (c) unfolded PVDF-MWCNT composite paper.

\section{Fabrication of coin cell}

For making the coin cell, $18 \mathrm{~mm}$ diameter circular disc was cut from the composite paper sample and dried in an 
oven. Free standing electrode (circular disk) was then assembled into 2032coin cell as anode in which lithium foil (Hoschen) was used as a counter electrode as shown in Fig. 3. Polypropylene film (Hoschen) was used as a separator and $1 \mathrm{M} \mathrm{LiPF}_{6}$ in 1:1 proportion of ethylene carbonate and diethyl carbonate (EC + DEC) (Merk) as an organic electrolyte. The complete cell was assembled inside the argon filled glove box. The cell was allowed to stabilize for $24 \mathrm{~h}$.

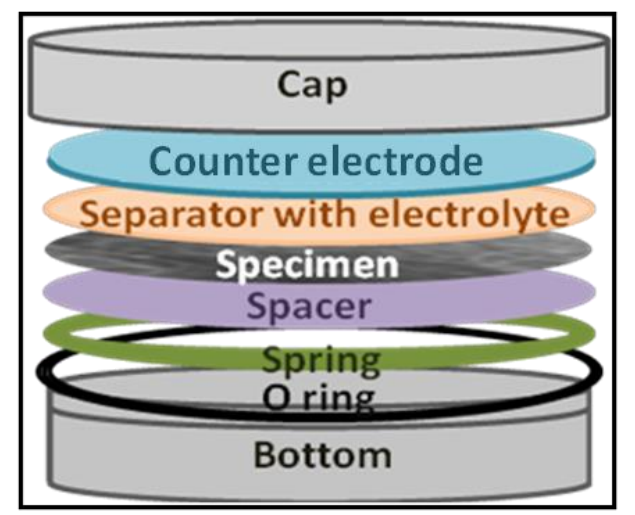

Fig. 3. Schematic of fabrication for Lithium ion coin cell.

\section{Characterization}

A Field Emission Scanning electron microscopy (FESEM) (Zeiss Supra-40VP) was used to study the morphologies of as produced MWCNTs, MWCNT paper and PVDF-MWCNT composite paper. High ResolutionTransmission Electron Microscope, Tecnai G20-string operated at $300 \mathrm{KV}$, was used for structural investigation. The Raman spectroscopy of the samples was carried out on a Renishaw inVia Raman spectrometer (UK) with laser excitation source of $514.5 \mathrm{~nm}$. The tensile strength of the MWCNT and PVDF-MWCNT composite paper was measured using an INSTRON machine (model 4411). The size of the sample was $40 \mathrm{~mm} \times 10 \mathrm{~mm}$. The thickness of the paper was measured at several points and an average taken for the measurement of cross-sectional area. The cross-head speed was maintained at $0.2 \mathrm{~mm} / \mathrm{min}$. The surface area of the composite paper was measured by $\mathrm{N}_{2}$ adsorption isotherm using Brunauer, Emmett and Teller (BET) method on an autosorb iQ automated gas sorption analyzer from Quantacrome Instruments, USA (model no. ASIQM0000-4). The electrical conductivity of the paper was measured by four-probe contact method using a Keithley 197 auto running advanced microvoltmeter and a Keithley 224 programmable current source. The values reported in the text are average of five readings at different places on the specimens. Galvanostatic charge/discharge characteristic of the individual coin cell was carried out at a current density of $100 \mathrm{~mA} / \mathrm{g}$. Electrochemical Impedance Studies were carried out by using an EG \& G instruments Model 5210 with an AC voltage signal of $5 \mathrm{mV}$ in the frequency range $100 \mathrm{KHz}$ to $5 \mathrm{mHz}$. The charge-discharge cycle was carried out at $\mathrm{C} / 10$ rate within the voltage window of $0.01-3.0 \mathrm{~V}$ at room temperature.

\section{Results and discussion}

\section{SEM, TEM and EDS}

The surface morphology of the samples was studied using FESEM. Fig. 4(a) \& 4(b) shows the scanning electron micrograph of PVDF-MWCNT composite paper at different magnification. It is observed that the MWCNTs are highly entangled with each other due to their high aspect ratio (long length). The physical interlocking of the tubes provides sufficient flexibility and handling strength to the paper to make it free standing. Inset of Fig. $\mathbf{4}(\mathbf{b})$ is the cross-sectional view of the same paper showing the average thickness of the PVDF-MWCNT composite paper to be $100 \mu \mathrm{m}$. From the micrograph of HRTEM (Fig. 4c) the diameter of the MWCNTs is observed 25-50 nm. The HRTEM micrograph of the samples clearly shows webs of thin PVDF matrix supporting the CNT porous network (Fig. 4d) which provides greater stability to the paper. The porosity favors the ion insertion/extraction and transportation [41]. The presence of iron catalyst between the walls of nanotube is also observed at some places (Fig. 4c) [42].

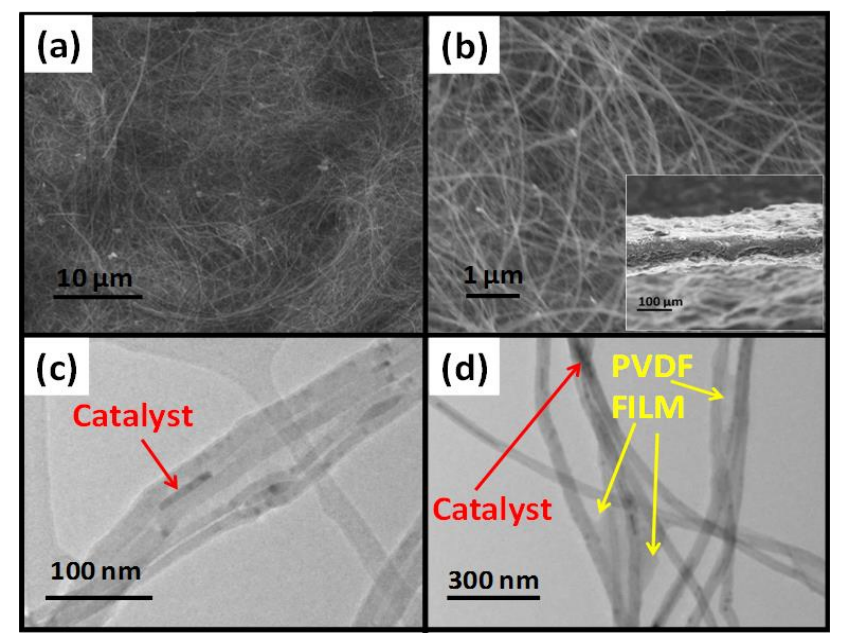

Fig. 4. (a \& b) Scanning electron micrograph of PVDF-MWCNT composite paper at different magnification and (c \& d) transmission electron micrograph of MWCNT paper and PVDF-MWCNT composite paper, respectively.

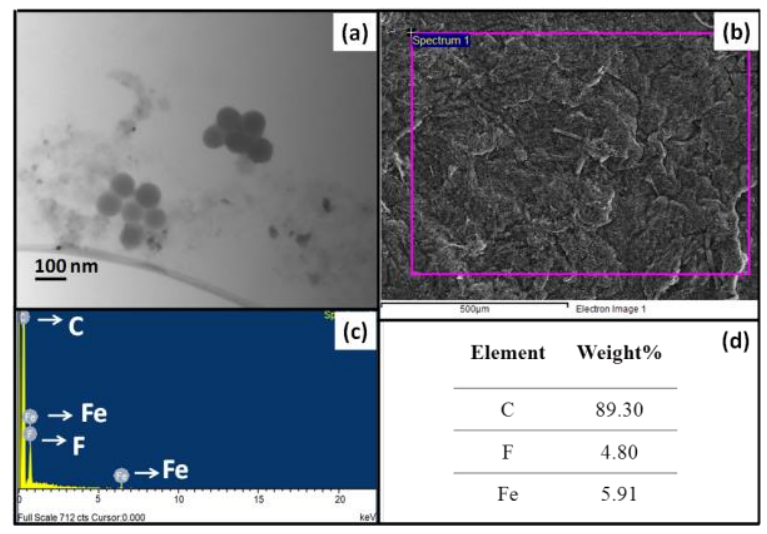

Fig. 5. (a) TEM image of PVDF powder, (b) SEM of scanned area of PVDF-MWCNT composite paper for EDS, (c) Count spectrum of composite paper and (d) Table of elements and weight percent found by EDS. 
Fig. 5(a) is the TEM image of the as such PVDF powder. The shape of the granules is almost spherical and approx. $80 \mathrm{~nm}$ in size. Fig. 5(b) is a small scanned area of the composite paper which is nearly $850 \mu \mathrm{m}^{2}$. Making use of the EDS of the PVDF-MWCNT composite paper (Fig. 5c) shows $4.8 \%$ of Fluorine by weight in the structure which amounts to $10 \%$ PVDF content in the composite paper which is nearly the same used initially as a binder. The iron content in the composite paper is found to be $5.91 \%$.

\section{XRD and Raman}

The X-ray diffraction pattern using PVDF is shown in Fig. 6(a). The CuK $\alpha$ radiation $(\lambda=1.54 \AA)$ was used as $\mathrm{X}$-ray source. Three prominent diffraction peaks were observed at $18.2^{\circ}, 19.9^{\circ}$, and $26.6^{\circ}$, which correspond to (020), (110), (021) diffraction planes respectively of the $\alpha$ phase of PVDF. The PVDF usually shows three phases $\alpha$, $\beta$ and $\gamma$. It therefore seems that the broad diffraction maxima around $2 \theta=40^{\circ}$ is due to diffraction maxima corresponding to (201) and (111) planes of the $\beta$ phase caused by the molecular head-head and tail-tail (HHTT) molecular arrangement [43].
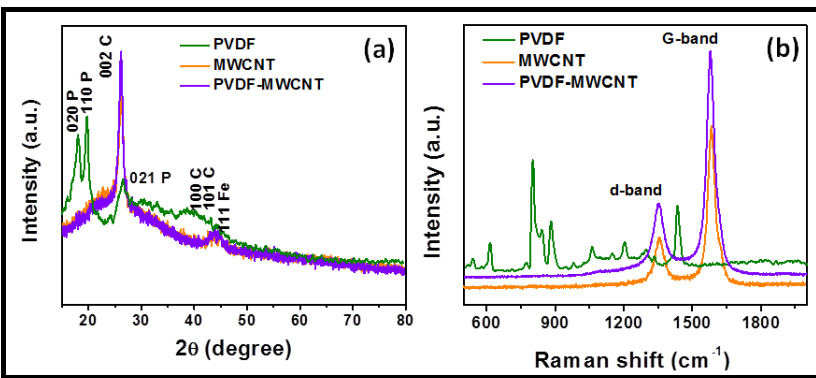

Fig. 6. (a) XRD pattern and (b) RAMAN spectra of PVDF powder, MWCNT paper and PVDF-MWCNT composite paper.

The XRD of MWCNT paper shows the prominent (002) diffraction maxima centered at $2 \theta=26^{\circ}$ due to basal planes of graphite [44]. There is not much difference in the diffraction pattern from the PVDF-MWCNT composite paper due to higher intensity of reflection from carbon rather than $10 \%$ PVDF as matrix. A broad diffraction maxima hump is observed between $42.3^{\circ}$ and $44.8^{\circ}$ due to unresolved (100) and (101) diffraction peaks of graphite.

Fig. 6 (b) shows the Raman spectra of PVDF powder with characteristic peaks at $536 \mathrm{~cm}^{-1}, 795 \mathrm{~cm}^{-1}, 839 \mathrm{~cm}^{-1}$, $882 \mathrm{~cm}^{-1}, 1296 \mathrm{~cm}^{-1}$ and $1428 \mathrm{~cm}^{-1}$ respectively [45,46]. The first order Raman spectra of the MWCNT paper shows two peaks at $1355 \mathrm{~cm}^{-1}$ and $1583 \mathrm{~cm}^{-1}$ corresponding to graphite D and G-band, respectively. However, these peaks shift to $1351 \mathrm{~cm}^{-1}$ (D-band) and $1578 \mathrm{~cm}^{-1}$ (G-band) due to the interaction between PVDF and nanotubes in the PVDF-MWCNT composite paper. The D-band is observed due to the longitudinal optical phonon induced by disordered carbon and coupled with the vibration of $\mathrm{sp}^{3}$ bonded carbon atom related to the diamond like structures. While, the G-band arises as a result of tangential shear mode of carbon atoms (matching to the $E_{2 g}$ mode) and typically associated with the vibration of $\mathrm{sp}^{2}$-bonded carbon atoms in a $2 \mathrm{D}$ hexagonal lattice, as seen in layers of graphene [47]. For polycrystalline graphite, it is observed that the intensity ratio $\mathrm{D}$ and $\mathrm{G}$-band $\left(\mathrm{I}_{\mathrm{D}} / \mathrm{I}_{\mathrm{G}}\right)$ is inversely proportional to the effective crystallite size of the graphite plane (La). The ratio is found to be nearly same i.e. 0.298 and 0.316 for MWCNT and PVDF-MWCNT for the two papers, suggesting that there is no damage to the nanotube structure due to high energy homogenizer used in the present study for dispersion.

\section{Electrical properties and surface area}

The calculated electrical conductivity of the MWCNT paper and PVDF-MWCNT composite paper is presented in Table 1. Electrical conductivity measurements are carried out at room temperature. Primarily, the electrical conductivity of neat MWCNT paper is found to be $30 \mathrm{~S} / \mathrm{cm}$. This high conductivity of paper is achieved due to the combine effect of high aspect ratio of MWCNT and interconnected conducting system provide by MWCNT, that results in a persistent charge distribution throughout the paper. On the other hand, in case of PVDF-MWCNT composite paper electrical conductivity decreases and is found to be $23 \mathrm{~S} / \mathrm{cm}$. This drop off is already expected due to the addition of PVDF which increases the interfacial resistance and hinder the movement of charge carriers. Thus, leads to decrease in electrical conductivity of PVDF-MWCNT composite paper. But this electrical conductivity is still high to transfer the charge easily.

Fig. 7 reveals that PVDF-MWCNT composite paper has significant potential in flexible electronics applications, such as irregularly shaped energy storage devices and other bendable displays. An experimental detailed Video of the flexible free-standing PVDFMWCNT composite paper is provided in the supplementary information.

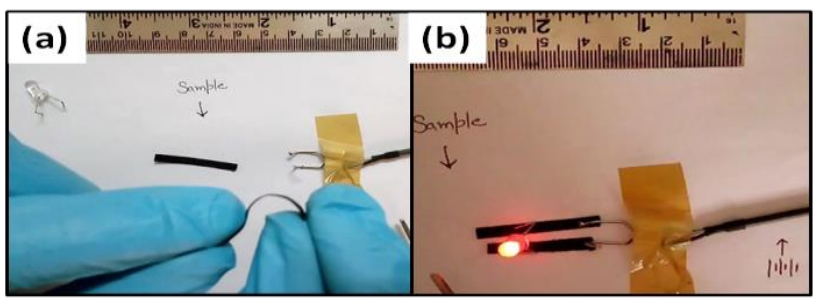

Fig. 7. (a) Digital image is showing the flexibility of PVDF-MWCNT composite paper electrode \& (b) shows a red LED glowing when connected to these electrodes.

The BET surface area of the MWCNT paper and PVDF-MWCNT composite paper is found to be $63 \mathrm{~m}^{2} / \mathrm{g}$ and $49 \mathrm{~m}^{2} / \mathrm{g}$, respectively (Table 1). The decrease in surface area is again due to the addition of PVDF which cover up the open pores and MWCNTs surface and decreases the overall surface area of composite paper.

Table 1. Electrical properties and surface area of MWCNT paper and PVDF-MWCNT composite paper. 


\begin{tabular}{lcc}
\hline Sample & $\begin{array}{c}\text { Conductivity } \\
(\mathrm{S} / \mathrm{cm})\end{array}$ & $\begin{array}{l}\text { BET surface } \\
\text { area }\left(\mathrm{m}^{2} / \mathrm{g}\right)\end{array}$ \\
\hline MWCNT paper & 30 & 63 \\
$\begin{array}{l}\text { PVDF-MWCNT } \\
\text { composite paper }\end{array}$ & 23 & 49 \\
\hline
\end{tabular}

\section{Mechanical testing}

Fig. 8, compares the stress-strain behavior of as produced MWCNT paper and PVDF-MWCNT composite paper under tensile load. It is observed that the fracture behavior of the two papers is quite different. As observed from the figure the MWCNT paper fails at a much lower load with a strain to failure of only $3.8 \%$. The calculated value of the corresponding tensile strength is also very poor i.e. $0.26 \mathrm{MPa}$. On the other hand, the PVDF-MWCNT composite paper shows the tensile strength of $3.5 \mathrm{MPa}$ and strain to failure of $11.25 \%$.

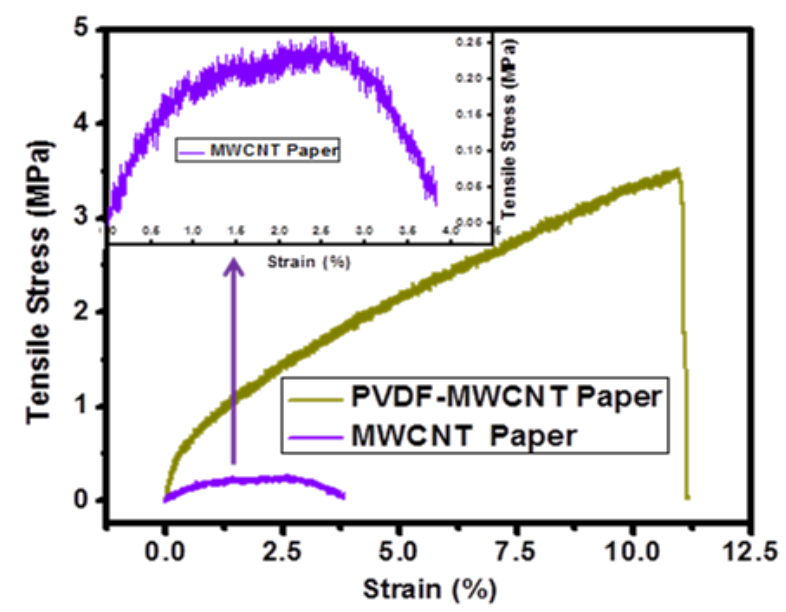

Fig. 8. Stress-Strain curves of MWCNT and PVDF-MWCNT composite Paper. Inset shows the enlarge view of the stress-strain curve of MWCNT paper.

The results show a good bonding of PVDF matrix with the porous CNT network as also revealed in the TEM micrograph of the sample in Fig. 4(d). Interestingly, a close look at the fracture surfaces of the two samples (Fig. 9) is quite different. In the sample without binder the crack propagates through the sample very easily leading to complete fracture of the sample at very low load. On the other hand, in the second sample the load is shared by the PVDF matrix and additional energy is consumed by the matrix to debond from the CNT leading to crack deflection.

The crack initiated from the other surface is also arrested before progressing catastrophically to the other end. The energy so absorbed in the samples therefore result into higher strength and strain to fracture of the composite sample. The high value of strain to fracture and strength along with higher flexibility will provide much needed robustness to the anode material during fabrication of battery and its longer life. Jia et. al. fabricated $\mathrm{V}_{2} \mathrm{O}_{5}$ nanowire based $\mathrm{CNT} / \mathrm{V}_{2} \mathrm{O}_{5}$ composite paper and measured the tensile strength value upto 4.7 $\mathrm{MPa}$ with strain to failure of only $2.8 \%$ [48]. They accredited the improvement in the mechanical performance of the composite electrode to the perforate structure of the long length PVDF coated MWCNTs $[48,49]$. However, the fabrication route in itself is quite complicated, first forming aero gel and later heating in an autoclave etc. The route adopted in the present study is much simpler comparatively.

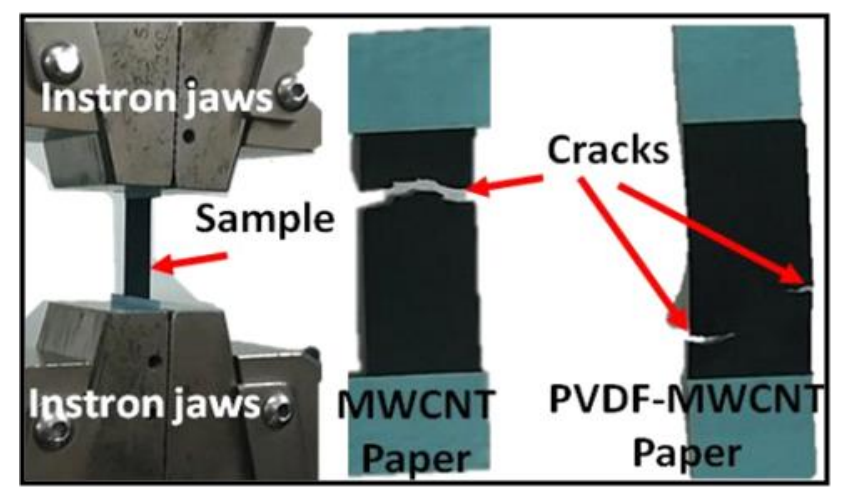

Fig. 9. Digital photographs of fractured samples of MWCNT and PVDF-MWCNT composite paper.

\section{Electrochemical studies}

Fig. 10(a) shows the galvanostatic charge/discharge characteristic of the unit coil cell after first, second and 50th cycles performed in the voltage range from $0.1 \mathrm{~V}$ to $3.0 \mathrm{~V}$ at a current density of $100 \mathrm{~mA} / \mathrm{g}$. The discharge behavior of the cell is much different in the second cycle as compared to first cycle due to the formation of solid electrolyte interface (SEI) layer on the anode [50,51]. As shown in the figure the charge capacity, which was 783 $\mathrm{mAh} / \mathrm{g}$ in the first cycle was reduced to $217 \mathrm{mAh} / \mathrm{g}$, after the second cycle, suggesting a Coulombic efficiency of $27 \%$ only. A close look at the first discharge cycle shows the presence of two distinct plateaus at $1.47 \mathrm{~V}$ and $0.79 \mathrm{~V}$ vs. $\mathrm{Li}^{+} / \mathrm{Li}$ signifying the structural transformation of the electrode due to $\mathrm{Li}$ insertion in the lattice. The low Coulombic efficiency for the first cycle can be ascribed to the formation of SEI layer. However, PVDF-MWCNT composite paper electrode shows indications of good electrochemical stability as well as capacity retention upto 50 cycles. This could be due to the presence of relatively high surface area and interconnected conducting network of the MWCNT which can make good contact with the electrolyte. Furthermore, researchers demonstrated that the interaction potential at the innermost region is dependent on the nanotubes diameter and MWCNTs with a diameter of 40-60 nm possesses greater interaction energy, which contribute in improving the $\mathrm{Li}$ storage capacity $[\mathbf{5 2 , 5 3}]$. This support our study as MWCNT used in composite paper have diameter upto $50 \mathrm{~nm}$ and together with PVDF provide better electrochemical performance and long cycle stability with good Coulombic efficiency.

As observed in Fig. 10(a), the voltage profiles become quite unusual with no perceptible voltage plateaus 
between these voltage ranges. However, after the initial drop the cycling performance of the cell with PVDFMWCNT anode shows a specific capacity of $170 \mathrm{mAh} / \mathrm{g}$ even after 50 cycles as shown in figure 10(b). The Coulombic efficiency reaches almost $98 \%$ showing excellent reversibility in the charge/discharge characteristics of the cell. The value of specific capacity is significantly higher with the additional advantage of flexibility and easy processing compare to our previous report [54].
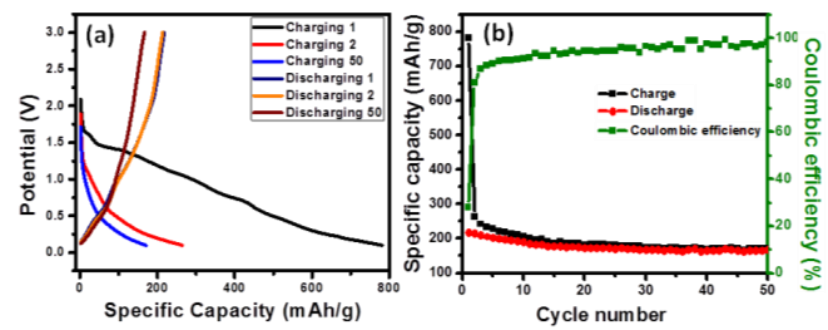

Fig. 10. (a) Electrochemical performance of the PVDF-MWCNT composite paper anodes showing 1st, 2nd and 5th cycle charge/discharge curves and (b) specific capacity and Coulombic efficiency vs. cycling number.

\section{Electrochemical impedance spectroscopy (EIS)}

For a typical lithium cell EIS provides excellent electroanalysis of the charge transfer reactions at the surface of the electrode, mass transport, double layer capacitance and the stability of the interface. In the present study, electrochemical impedance spectroscopy (EIS) of the sample was carried out by the using galvanostatic charge/discharge cycles upto fifty cycles in the frequency range of $100 \mathrm{kHz}$ to $5 \mathrm{mHz}$. A common way to display the impedance of a system is with a Nyquist plot shown in Fig. 11(a) in which the negative imaginary component of impedance is plotted against the real component of impedance.
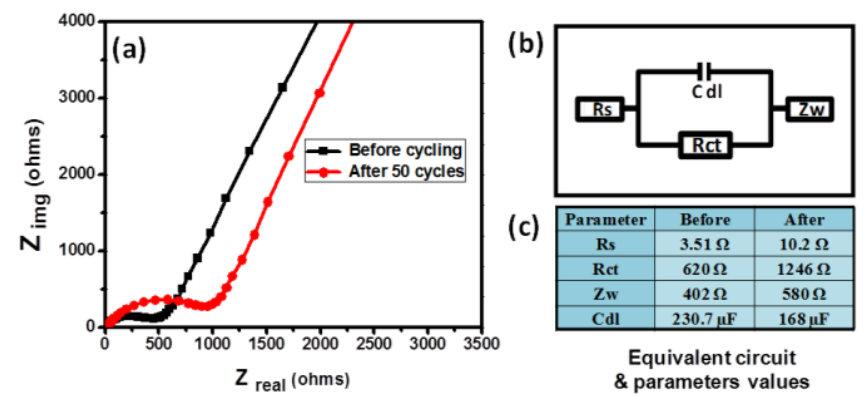

Fig. 11. (a) Nyquist plot of the PVDF-MWCNT composite paper before and after cycling, (b) the equivalent circuit and (c) table shows the parameters values of the equivalent circuit.

The Nyquist plot shows an increase in the diameter of the semicircle with the number of cycles with almost zero to $1000 \mathrm{ohm}$ due to combination of charge transfer resistance, capacitance and surface reactions at the electrode, forming SEI. This semi-circle is followed by a tail which is principally affected by the diffusion within the electrolyte and active electrode material $[\mathbf{5 5 , 5 6}]$. The impedance spectra for PVDF-MWCNT composite paper electrode can be modeled by an equivalent circuit in order to fit the EIS response. The equivalent circuit is provided in the Fig. 11(b), which is formed from the arrangement of a capacitance, resistance and constant phase element of the anode. The parameters were calculated after fitting the impedance plot and given in the Table of Fig. 11(c). In equivalent circuit the $R_{s}$ is the resistance due to surface film (SEI) formed on the outer surface of the electrode, $\mathrm{R}_{\mathrm{ct}}$ and $\mathrm{C}_{\mathrm{dl}}$ is the charge transfer resistance and the double layer capacitance, respectively, while $Z_{\mathrm{W}}$ is the Warburg impedance represents the diffusion of $\mathrm{Li}$-ions in bulk of composite paper electrode. Values of all the parameters based on fitting EIS data are given in table of Fig. 11(c). After analyzing the data, it can be seen clearly that $R_{s}$ and $R_{c t}$ increases after cycling while $\mathrm{C}_{\mathrm{dl}}$ decreases after cycling. A possible reason for this change can be linked to the structural stability of PVDF-MWCNT composite paper. The charge transfer resistance (distance across of the half circle) increases after 50 cycles because of SEI development in initial cycles and a stable SEI layer which does not crack after cycling thus increases the resistance and decreases the capacitance value. Due to the formation of SEI layer some irreversible capacity appears. The PVDF-MWCNT structure provides a robust and stable anode. The electrode kept its structure unchanged with an interpenetrating system and shows it's mechanical robustness. Therefore, with advantages of straightforward vacuum filtration techniques for composite paper preparation and encouraging electrochemical performance, PVDF-MWCNT composite paper can be used as potential candidates as an anode material of next-generation LIB. Additionally, the freestanding composite paper electrode is prepared with reasonably reduced cost as no conductivity additive and copper current collector were used.

\section{Conclusions}

It has been possible to produce flexible, light-weight, electrically conducting and free-standing PVDF-MWCNT composite paper with tensile strength of $3.5 \mathrm{MPa}$ at $11.25 \%$ strain to failure. It is therefore possible to eliminate copper substrate and increase the overall charge density of the anode. The in-house prepared large aspect ratio MWCNT were well dispersed in the solvent with the help of high energy homogenizer before processing into a flexible paper using in-house assembled vacuum filtration unit. The electrochemical performance of composite paper shows a high reversible limit of $170 \mathrm{mAh} / \mathrm{g}$ at a current density of $100 \mathrm{~mA} / \mathrm{g}$, and having Coulombic efficiency more than $98 \%$ even after fifty cycles. The flexible, light-weight and free-standing PVDF-MWCNT composite paper could be a suitable candidate as anode material for flexible or bendable next generation $\mathrm{Li}$-ion batteries.

\section{Acknowledgements}

The authors would like to thank to the Director CSIR-National Physical Laboratory, India, for taking interest in the work and give his permission to publish this work. We would also like to extend their sincere thank to 
Mrs. Shaveta Sharma for mechanical testing and Raman analysis of the samples, Mr. R.K. Seth for BET surface area measurements, Dr. V.P.S. Awana and Dr. N. Vijayan for XRD, Mr. Dinesh Singh for HRTEM and Mr. M. Saravanan for FESEM characterization. This work was carried under CSIR-TAPSUN (NWP-56) project on "Innovative Solution for Solar Energy Storage".

\section{References}

1. Guler, M. O.; Cetinkaya, T.; Uysal, M.; Akbulut, H.; International Journal of Energy Research 2015, 39, 172.

DOI: $10.1002 / \mathrm{er} .3220$

2. Goodenough, J. B.; Kim, Y.; Chemistry of Materials 2010, 22, 587. DOI: $10.1021 / \mathrm{cm} 901452 \mathrm{z}$

3. Shi, L.; Li, H.; Wang, Z.; Huang, X.; Chen, L.; Journal of Materials Chemistry 2001, 11, 1502.

DOI: $10.1039 / \mathrm{b} 009907 \mathrm{o}$

4. Park, M.; Zhang, X.; Chung, M.; Less, G. B.; Sastry, A. M.; Journal of Power Sources 2010, 195, 7904.

DOI: 10.1016/j.jpowsour.2010.06.060

5. Zhang, L.-S.; Jiang, L.-Y.; Yan, H.-J.; Wang, W. D.; Wang, W.; Song, W.-G.; Guo, Y.-G.; Wan, L.-J.; Journal of Materials Chemistry 2010, 20, 5462.

DOI: $10.1039 / \mathrm{c} 0 \mathrm{jm} 00672 \mathrm{f}$

6. Xu, X.-B.; Geng, H.-Z.; Meng, Y.; Ding, E.-X.; Wang, Y.; Zhang, Z.-C.; Wang, W.-Y.; Materials Chemistry and Physics 2015, 153, 155.

DOI: $10.1016 /$ j.matchemphys.2014.12.047

7. Lou, X. W.; Deng, D.; Lee, J. Y.; Feng, J.; Archer, L. A.; Adv. Mater. 2008, 20, 258.

DOI: $10.1002 / \mathrm{adma} .200702412$

8. Li, Y.; Tan, B.; Wu, Y.; Nano Lett. 2008, 8, 265. DOI: $10.1021 / \mathrm{nl} 0725906$

9. Meduri, P.; Pendyala, C.; Kumar, V.; Sumanasekera, G. U.; Sunkara, M. K.; Nano Lett. 2009, 9, 612.

DOI: $10.1021 / \mathrm{n} 1802864 \mathrm{a}$

10. Ban, C.; Wu, Z.; Gillaspie, D. T.; Chen, L.; Yan, Y.; Blackburn, J. L.; Dillon, A. C.; Adv. Mater. 2010, 22, E145. DOI: 10.1002/adma.200904285

11. Ramos-Sanchez, G.; Chen, G.; Harutyunyan, A. R.; Balbuena, P. B.; RSC Advances 2016, 6, 27260. DOI: $10.1039 / \mathrm{c} 5 \mathrm{ra} 27225 \mathrm{~d}$

12. Wang, S.; Zhang, J.; Chen, C.; J. Power Sources 2010, 195, 5379. DOI: $10.1016 / j$ j.jpowsour.2010.03.035

13. Bulusheva, L. G.; Arkhipov, V. E.; Fedorovskaya, E. O.; Zhang, S.; Kurenya, A. G.; Kanygin, M. A.; Asanov, I. P.; Tsygankova, A. R.; Chen, X. H.; Song, H. H.; Okotrub, A. V.; Journal of Power Sources 2016, 311, 42.

DOI: $10.1016 / j . j p o w s o u r .2016 .02 .036$

14. Pasero, D.; Reeves, N.; West, A. R.; J. Power Sources 2005, 141, 156. DOI: $10.1016 /$ j.jpowsour.2004.07.037

15. Noerochim, L.; Wang, J.-Z.; Chou, S.-L.; Wexler, D.; Liu, H.-K.; Carbon 2012, 50, 1289.

DOI: $10.1016 / j$. carbon.2011.10.049

16. Chew, S. Y.; Ng, S. H.; Wang, J.; Novák, P.; Krumeich, F.; Chou, S. L.; Chen, J.; Liu, H. K.; Carbon 2009, 47, 2976. DOI : 10.1016/j.carbon.2009.06.045

17. Verrelli, R.; Hassoun, J.; ChemElectroChem 2015, 2, 988. DOI: $10.1002 /$ celc. 201500069

18. Landi, B. J.; Ganter, M. J.; Cress, C. D.; DiLeo, R. A.; Raffaelle, R. P.; Energy \& Environmental Science 2009, 2, 638. DOI: $\underline{10.1039 / \mathrm{b} 904116 \mathrm{~h}}$

19. Maurin, G.; Henn, F.; Simon, B.; Colomer, J. F.; Nagy, J. B.; Nano Letters 2001, 1, 75.

DOI: $10.1021 / \mathrm{n} 1005517 \mathrm{n}$

20. Lin, K.; Xu, Y.; He, G.; Wang, X.; Materials Chemistry and Physics 2006, 99, 190. DOI: $10.1016 / \mathrm{j}$. matchemphys.2005.09.035

21. Yang, S.; Song, H.; Chen, X.; Okotrub, A. V.; Bulusheva, L. G.; Electrochimica Acta 2007, 52, 5286.

DOI: $10.1016 /$ j.electacta.2007.02.049

22. Ng, S. H.; Wang, J.; Guo, Z. P.; Chen, J.; Wang, G. X.; Liu, H. K.; Electrochimica Acta 2005, 51, 23.
DOI: $10.1016 /$ j.electacta.2005.04.045

23. DiLeo, R. A.; Ganter, M. J.; Landi, B. J.; Raffaelle, R. P.; Journal of Materials Research 2010, 25, 1441.

DOI: 10.1557/JMR.2010.0184

24. Reddy, A. L. M.; Srivastava, A.; Gowda, S. R.; Gullapalli, H.; Dubey, M.; Ajayan, P. M.; ACS Nano 2010, 4, 6337.

DOI: $10.1021 / \mathrm{nn} 101926 \mathrm{~g}$

25. Vinayan, B. P.; Nagar, R.; Raman, V.; Rajalakshmi, N.; Dhathathreyan, K. S.; Ramaprabhu, S.; Journal of Materials Chemistry 2012, 22, 9949.

DOI: $10.1039 / \mathrm{c} 2 \mathrm{jm} 16294 \mathrm{f}$

26. Xin, F.-X.; Tian, H.-J.; Wang, X.-L.; Xu, W.; Zheng, W.-G.; Han, W.-Q.; ACS Applied Materials \& Interfaces 2015, 7, 7912. DOI: $10.1021 / \mathrm{am} 508547 \mathrm{~g}$

27. Hu, Y.; Li, X.; Wang, J.; Li, R.; Sun, X.; Journal of Power Sources 2013, 237, 41.

DOI: $\underline{10.1016 / j . j p o w s o u r .2013 .02 .065}$

28. Lingappan, N.; Van, N. H.; Lee, S.; Kang, D. J.; Journal of Power Sources 2015, 280, 39. DOI: $10.1016 / j . j p o w s o u r .2015 .01 .064$

29. Yu, A.; Park, H. W.; Davies, A.; Higgins, D. C.; Chen, Z.; Xiao, $\mathrm{X}$.; The Journal of Physical Chemistry Letters 2011, 2, 1855. DOI: $10.1021 / \mathrm{jz} 200836 \mathrm{~h}$

30. Elizabeth, I.; Mathur, R.; Maheshwari, P.; Singh, B.; Gopukumar, S.; Electrochimica Acta 2015, 176, 735

DOI: $10.1016 /$ j.electacta.2015.06.156

31. Stephenson, T.; Li, Z.; Olsen, B.; Mitlin, D.; Energy \& Environmental Science 2014, 7, 209. DOI: $10.1039 / \mathrm{C} 3 \mathrm{EE} 42591 \mathrm{~F}$

32. Bhaskar, A.; Deepa, M.; Narasinga Rao, T.; ACS Applied Materials \& Interfaces 2013, 5, 2555.

DOI: $\underline{10.1021 / \mathrm{am} 3031536}$

33. Zhang, W.-M.; Hu, J.-S.; Guo, Y.-G.; Zheng, S.-F.; Zhong, L.-S.; Song, W.-G.; Wan, L.-J.; Advanced Materials 2008, 20, 1160. DOI: 10.1002/adma.200701364

34. Cui, L.-F.; Hu, L.; Choi, J. W.; Cui, Y.; ACS Nano 2010, 4, 3671. DOI: $10.1021 / \mathrm{nn} 100619 \mathrm{~m}$

35. Maurin, G.; Bousquet, C.; Henn, F.; Bernier, P.; Almairac, R.; Simon, B.; Chemical Physics Letters 1999, 312, 14.

DOI: 10.1016/S0009-2614(99)00886-6

36. Yan, J.; Song, H.; Yang, S.; Yan, J.; Chen, X.; Electrochimica Acta 2008, 53, 6351.

DOI: $10.1016 /$ j.electacta.2008.04.048

37. Wang, X. X.; Wang, J. N.; Su, L. F.; Journal of Power Sources 2009, 186, 194. DOI: $10.1016 / j$ j.jpowsour.2008.09.074

38. Frackowiak, E.; Gautier, S.; Gaucher, H.; Bonnamy, S.; Beguin, F.; Carbon 1999, 37, 61.

DOI: $10.1016 / \mathrm{S} 0008-6223(98) 00187-0$

39. Mathur, R. B.; Chatterjee, S.; Singh, B. P.; Composites Science and Technology 2008, 68, 1608.

DOI: $10.1016 /$ j.compscitech.2008.02.020

40. Xu, J.; Liu, Y.; He, L.; Zhang, C.; Zhang, Y.; Ceramics International 2016, 42, 12027.

DOI: $\underline{10.1016 / \text { j.ceramint.2016.04.129 }}$

41. Singh, D. K.; Iyer, P. K.; Giri, P. K.; Diamond and Related Materials 2010, 19, 1281.

DOI: $10.1016 /$ j.diamond.2010.06.003

42. Lovinger, A. J.; Davis, D. D.; Cais, R. E.; Kometani, J. M.; Polymer 1987, 28, 617.

DOI: 10.1016/0032-3861(87)90478-2

43. Ye, M.; Hu, C.; Lv, L.; Qu, L.; Journal of Power Sources 2016, $305,106$.

DOI: $10.1016 /$ j.jpowsour.2015.11.098

44. Satapathy, S.; Pawar, S.; Gupta, P. K.; Varma, K. B. R.; Bulletin of Materials Science 2011, 34, 727.

DOI: $10.1007 / \mathrm{s} 12034-011-0187-0$

45. Kobayashi, M.; Tashiro, K.; Tadokoro, H.; Macromolecules 1975, 8,158 .

DOI: $10.1021 / \mathrm{ma} 60044 \mathrm{a} 013$

46. Chaudhary, A.; Kumari, S.; Kumar, R.; Teotia, S.; Singh, B. P.; Singh, A. P.; Dhawan, S.; Dhakate, S. R.; ACS applied materials \& interfaces 2016, 8, 10600 .

DOI: $\underline{10.1021 / a c s a m i .5 b 12334}$ 
47. Jia, X.; Chen, Z.; Suwarnasarn, A.; Rice, L.; Wang, X.; Sohn, H.; Zhang, Q.; Wu, B. M.; Wei, F.; Lu, Y.; Energy \& Environmental Science 2012, 5, 6845.

DOI: $10.1039 / \mathrm{c} 2 \mathrm{ee} 03110 \mathrm{~h}$

48. Zhang, Q.; Zhao, M.; Liu, Y.; Cao, A.; Qian, W.; Lu, Y.; Wei, F.; Advanced Materials 2009, 21, 2876.

DOI: $10.1002 / \mathrm{adma} .200900123$

49. Shin, H.; Park, J.; Sastry, A. M.; Lu, W.; Journal of Power Sources 2015, 284, 416. DOI: $10.1016 /$ j.jPowsour.2015.03.039

50. Park, S. H.; Kim, H. J.; Lee, J.; Jeong, Y. K.; Choi, J. W.; Lee, H.; ACS Applied Materials \& Interfaces 2016, 8, 13973.

DOI:10.1021/acsami.6b04109

51. Xiong, Z.; Yun, Y. S.; Jin, H.-J.; Materials 2013, 6, 1138.

DOI: $10.3390 / \mathrm{ma} 6031138$

52. Zhang, Y.; Chen, T.; Wang, J.; Min, G.; Pan, L.; Song, Z.; Sun, Z.; Zhou, W.; Zhang, J.; Applied Surface Science 2012, 258, 4729. DOI:10.1016/j.apsusc.2012.01.067

53. Teotia, S.; Singh, B. P.; Elizabeth, I.; Singh, V. N.; Ravikumar, R.; Singh, A. P.; Gopukumar, S.; Dhawan, S. K.; Srivastava, A.; Mathur, R. B.; RSC Advances 2014, 4, 33168. DOI: $10.1039 / \mathrm{c} 4 \mathrm{ra} 04183 \mathrm{f}$

54. Ren, Y.; Wu, X.; Li, M.; Electrochimica Acta 2016, 206, 328. DOI:10.1016/j.electacta.2016.04.161

55. Mondal, A. K.; Liu, H.; Xie, X.; Kretschmer, K.; Wang, G.; Chem Plus Chem 2016, 81, 399.

DOI: $10.1002 /$ cplu. 201500528

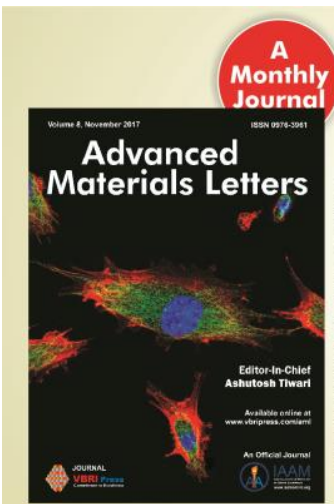

\section{Publish} your article in this journal

Advanced Materials Letters is an official international journal of International Association of Advanced Materials (IAAM, www.iaamonline.org) published monthly by provide high-quality perreview articles in the fascin to field of materials sciencond area structure synthesis and processing. area strocture, synthesis and processing. charactisation, advanced-state properties and applications of materals. Al published articles are for free. The manuscript management system is for free. The manuscript management system is complete the journal indudes review ant peer-review proces. The journal includes review anticle, research 